\title{
Inserção no mercado de trabalho e a empregabilidade de bacharéis em Biblioteconomia
}

\author{
Priscila Reis dos Santos \\ Graduação em Biblioteconomia.Mestrado em \\ Administração
}

José Marcos Carvalho de Mesquita

Economista, Mestre e Doutor em Administração, professor da Universidade Fumec

Jorge Tadeu de Ramos Neves

Graduação em Engenharia Metalúrgica, Economia e Administração.Mestrado e Doutorado em Génie Industriel et Gestion de Linnovation Technologique Pós Doutorado em Empreendedorismo e Inovação

Alessandra Mesquita Bastos

Graduação em Administração, Publicidade e
Propaganda e Educação Física.Mestre em
Administração

http://dx.doi.org/10.1590/1981-5344/2563

A atuação do bibliotecário está cada vez menos limitada às bibliotecas e esse trabalhador, atualmente conhecido como profissional da informação, enfrenta o desafio de inserir-se e manter-se atrativo no mercado de trabalho, que está cada vez mais exigente e competitivo. Para manter-se empregável, ele precisa, constantemente, aprimorar os seus conhecimentos e desenvolver suas habilidades técnicas e pessoais por meio da educação e treinamento, ambos em consonância com as necessidades do mercado. O objetivo desta pesquisa é analisar a inserção profissional e a empregabilidade dos bacharéis em Biblioteconomia, egressos da Escola de Ciência da Informação da UFMG no interstício 20052010, no mercado de trabalho de Belo Horizonte. Para isso, foi aplicado em 74 indivíduos, um questionário semiestruturado contendo perguntas fechadas e abertas. Os dados foram analisados por meio da análise de conteúdo, análise exploratória de dados, tabulação cruzada e análise fatorial exploratória. Os resultados indicaram que $91 \%$ dos entrevistados estão empregados e $97 \%$ conseguiram o emprego no primeiro ano após a conclusão do curso. Os fatores identificados como responsáveis pela inserção do profissional no mercado de trabalho foram: "habilidades e competências profissionais" e "valores e atitudes do bibliotecário". 
Palavras-chave: Bibliotecário; Mercado de trabalho; Empregabilidade.

\section{Insertion in the labor market and the employability of graduates in Library}

The role of the librarian is becoming less limited to libraries and the employee, now known as information professionals faces the challenge of entering into and remain attractive in the modern labor market, which is increasingly demanding and competitive. To remain employable, he or she needs to constantly improve their knowledge and develop their technical and personal skills through education and training, both in line with market needs. To analyze the professional insertion and employability of graduates in Library, graduated from the ECI/UFMG during 2005-2010, in the labor market of Belo Horizonte is the guiding objective of this research. Based on the results, we found that $91 \%$ of respondents are employed and $97 \%$ got the job in the first year after conclusion. The factors identified as responsible for the professional insertion in the labor market were "skills and professional competence" and "values and Librarian attitudes".

\section{Keywords: Librarian; Labor market; Employability.}

Recebido em 21.09.2015 Aceito em 25.04.2016

\section{Introdução}

A atuação do bibliotecário, profissional academicamente preparado para selecionar, tratar, recuperar e disseminar informações, está cada vez menos limitada às bibliotecas. (BARBOSA, 1998; SANTA ANNA; PEREIRA, 2014). Para Barbosa (1998), a aplicação do conhecimento tradicional de Biblioteconomia em novos contextos auxiliará no desenvolvimento de oportunidades no mercado de trabalho para esses profissionais. Contudo, essa inserção não ocorre apenas devido à pluralidade da formação deles, mas também, em decorrência do surgimento das novas tecnologias de informação e comunicação e das mudanças ocorridas no mercado de trabalho, em que a relação empregado $X$ empregador têm se tornado mais frágil e flexível.

O vínculo empregatício está cedendo espaço para novos modelos de relacionamento profissional. O profissional da informação pode atuar como 
técnico, gerente, consultor, prestador de serviços por temporada e empreendedor (MINARELLI, 1995). Segundo Lemos (2006), para atender às exigências de tarefas dessas diferentes possibilidades de atuação, o bibliotecário necessita constantemente capacitar-se. Entretanto, há estudos demonstrando que a capacitação acadêmica, isoladamente, não garante a inserção profissional, embora seja imprescindível para melhorar as condições de empregabilidade. Minarelli (1995) afirma que o conhecimento, habilidades e atitudes pessoais, desenvolvidas por meio da educação e treinamentos focados com as necessidades do mercado, facilita a inclusão profissional.

A empregabilidade dos profissionais da informação tem sido abordada em pesquisas desenvolvidas em diversas localidades e até com abrangência nacional. Contudo, são desconhecidas pesquisas desta natureza que tenham como foco o bibliotecário atuante em Belo Horizonte. Na capital mineira, dezenas de bacharéis em Biblioteconomia graduam-se anualmente pela Escola de Ciência da Informação (ECI) da Universidade Federal de Minas Gerais (UFMG) e, dentre estes, acredita-se que muitos são absorvidos pelo "mercado informacional tradicional", composto por bibliotecas universitárias, escolares, técnicas e administração pública. Há ainda os bibliotecários que se tornam empreendedores e consultores e a expectativa é de que alguns atuem em setores menos tradicionais, sem, no entanto, abandonar a práxis bibliotecária. Os bibliotecários que atuam em contextos menos usuais, que conforme Valentim (2000 apud MOTA e OLIVEIRA, 2005), podem ser chamados de "mercado informacional de tendências" e "mercado informacional existente e não-ocupado", constituem uma parcela de precursores que possibilitam o desenvolvimento de novas oportunidades no mercado de trabalho para os profissionais que irão sucedê-los.

Diante do desconhecimento acerca de pesquisas atualizadas que abordem tal aspecto e da importância destes estudos para a consolidação profissional, surge a seguinte questão: "Como ocorre, sob a percepção dos egressos da ECI/UFMG entre 2005 e 2010, a inserção e a empregabilidade destes profissionais no mercado de trabalho informacional tradicional; informacional de tendências; informacional existente e pouco ocupado - em Belo Horizonte"?

Dessa forma, o objetivo geral é analisar a inserção profissional e a empregabilidade dos bacharéis em biblioteconomia, egressos da ECI/UFMG no interstício 2005-2010, no mercado de trabalho em Belo Horizonte. Os objetivos específicos são: 1) caracterizar os profissionais do grupo de bacharéis em biblioteconomia egressos da ECI/UFMG no período de 2005 a 2010; 2) verificar a inserção desses profissionais no mercado de trabalho em Belo Horizonte e 3) identificar os fatores que contribuem para a empregabilidade do grupo pesquisado.

Barbosa (1998), Arruda et al. (2000), Valetim (2000), Loureiro e Januzzi (2005) têm utilizado a terminologia "profissional da informação" para designar o bibliotecário. No entanto, esta denominação, conforme a Classificação Brasileira de Ocupações (CBO) (BRASIL, 2003), de forma 
genérica, acolhe também diversos outros profissionais, tais como os documentalistas e analistas de informação. Entretanto, neste estudo, e em consonância com a Ciência da Informação, o termo profissional da informação será empregado para referir-se exclusivamente aos bibliotecários, bacharéis egressos em Biblioteconomia.

\section{Referencial teórico}

\subsection{Bibliotecário}

Para Partridge, Menzies, e Munro (2010), o papel das bibliotecas atualmente não se restringe apenas à oferta de livros e informações, mas sobretudo à capacidade de oferecem meios para que haja interação e participação entre pessoas. As bibliotecas assumem um papel dinâmico em função da evolução tecnológica dos dias atuais.

Sendo assim, o bibliotecário é o profissional que pode desempenhar funções técnicas ou administrativas em uma biblioteca e tem como responsabilidades gerir, conservar, organizar, garantir o seu bom funcionamento e o bom atendimento ao público (CUNHA; CAVALCANTI, 2008; FARIA; PERICÃO, 2008), aumentar as coleções, classificá-las e tratar os documentos que estiverem em quaisquer suportes recuperando assim, o conteúdo informacional (FARIA; PERICÃO, 2008).

Segundo Brasil (2003), os profissionais da informação podem trabalhar em bibliotecas, centros de informação, centros de documentação, redes, sistemas de informação e prestar serviços de assessoria e consultoria. Eles devem desenvolver estudos, pesquisas e ações educativas, difundindo assim a cultura. Precisam demonstrar raciocínio lógico, pró-atividade, criatividade, capacidade de concentração, de análise e síntese; capacidade empreendedora, de comunicação e de negociação; conhecimento de outros idiomas; senso de organização, agir com ética, manter-se atualizado, liderar equipes e trabalhar em equipe e em rede.

Para Cunha e Cavalcanti (2008), no Brasil, a profissão de bibliotecário é privativa dos bacharéis em Biblioteconomia. A Lei n.o 4.084, de 30 de junho de 1962 (BRASIL, 1962), estabelece tal restrição e impede que outros profissionais atuem em áreas e atividades que são exclusivas do profissional da informação. Para exercer legalmente a profissão, o bibliotecário precisa estar registrado no conselho de Biblioteconomia da região na qual atua. Atuar sem registro ou sem o pagamento da taxa de anuidade implica em exercício ilegal da profissão.

Em Belo Horizonte, essa ilegalidade é coibida pela ação fiscalizatória do Conselho Regional de Biblioteconomia da $6^{a}$ Região. Dentre outras atribuições estabelecidas pelo Regimento Interno do Conselho Federal de Biblioteconomia (CFB), compete ao CRB fiscalizar o exercício da profissão, punindo infratores e encaminhando, para as autoridades competentes, relatórios documentados acerca de fatos apurados cuja solução não seja de responsabilidade do órgão (BRASIL, 2003). 
De acordo com Arruda et al. (2000), o surgimento da tecnologia da informação ampliou e redimensionou o campo de atuação desses profissionais, mas também trouxe a eles novos desafios. Por isso, Barbosa (1998) salienta a importância dos bibliotecários prepararem-se para aplicarem seus conhecimentos técnicos em outros cenários informacionais que não sejam apenas em bibliotecas. Assim, é neste contexto pósmoderno que a empregabilidade dos indivíduos passa a ser amplamente discutida (NÁDER; OLIVEIRA, 2007).

\subsection{Carreiras e empregabilidade}

Conforme Kilimnik et al. (2008); Haynie; Shepherd (2011) e Wilkoszynski; Vieira (2013), as carreiras podem ser divididas em tradicionais e modernas. O modelo tradicional caracteriza-se pela estabilidade no emprego (SULLIVAN; BARUCH, 2009), progressão linear e ascendente na escala hierárquica e pela responsabilidade das organizações em administrar as carreiras dos trabalhadores (VOS; SOENS, 2008; WILKOSZYNSKI; VIEIRA, 2013). Nas décadas passadas era comum um trabalhador desenvolver toda a sua trajetória profissional em uma única organização, mantendo o chamado emprego por toda a vida.

Até a década de 1990, a carreira tradicional predominava na sociedade (TIEPPO et al., 2011). As modernizações tecnológicas provocaram diversas mudanças nas relações de trabalho que se tornaram mais frias, frágeis e utilitárias. Houve redução dos postos de trabalho (causado por downsizing, reengenharia, fusões, entre outros), subcontratações, utilizações de autônomos e terceirizados, facilitação dos processos de desligamento e elevação no índice de rotatividade. Trabalhadores passaram a serem estimulados a desligar-se de uma organização e constituírem uma empresa para poder prestar serviços de assessoria à instituição que os demitiu. A lealdade total à empresa, característica da carreira tradicional, foi substituída pelo comportamento individualista do trabalhador, que utiliza seu tempo na organização como uma oportunidade de adquirir conhecimento, desenvolver e ampliar sua rede de contatos.

Assim, as carreiras tradicionais foram sendo substituídas pelas carreiras proteanas e autogeridas (HELAL et al., 2007). A carreira proteana é mais flexível, podendo desenvolver-se tanto horizontalmente quanto verticalmente e a responsabilidade pelo sucesso profissional passa a ser do indivíduo (VOS; SOENS, 2008; GOMES et al., 2011). Ela é administrada conforme os valores pessoais e profissionais e é marcada pelas escolhas sucessivas do indivíduo. Assim, ele pode ter mais de uma carreira durante a sua vida (LEMOS, 2006; HAYNIE; SHEPHERD, 2011) e até mesmo, pode trabalhar simultaneamente em mais de uma organização para obter mais conhecimentos e complementar os seus rendimentos (KILIMNIK et al., 2008; HEIJDEN et al., 2009). O mercado de trabalho tem sido flexível e multifuncional $e$ isso possibilita que os 
profissionais atuem em diversos ramos, e até mesmo, em áreas diferentes das de suas formações.

Para Kilimnik et al. (2008), Heijden et al. (2009) e Lemos et al. (2011), a carreira proteana requer indivíduos mais pró-ativos, capacitados e atualizados. Ela confere autonomia ao profissional e determina o incremento da sua capacidade técnica, polivalência na sua atuação e desenvolvimento das suas habilidades pessoais para que o indivíduo mantenha-se empregável. Para Náder e Oliveira (2007), empregabilidade é a tarefa do trabalhador de ajustar-se às condições de trabalho, ou seja, consiste na empregabilidade de iniciativa.

\subsection{0 mercado de trabalho do bibliotecário}

Os bibliotecários, profissionais conhecidos tradicionalmente pela habilidade em gerenciar acervos bibliográficos contidos em suportes tangíveis, tais como livros, periódicos, recursos audiovisuais e mapas, passam a atuar em outros ambientes e em novos suportes. Eles são drasticamente afetados pelo declínio do emprego formal, pela informatização do ambiente de trabalho, pelo avanço das tecnologias da informação e comunicação, pelo crescimento do emprego parcial e precarização do emprego, pela rápida desqualificação do trabalhador, por processos de reengenharia, terceirização, entre outros. Por isso, para manterem-se atrativos para o mercado e poderem alcançar o sucesso profissional, eles precisam, de forma mais exacerbada, caracterizar-se pelo polimorfismo e versatilidade. Baptista e Mueller (2005, p. 44) ainda acrescentam que eles devem ser criativos, inovadores, capazes de se comunicarem eficientemente e de perceber oportunidades em novos contextos.

O mercado de trabalho do bibliotecário, para Valentim (2000 apud MOTA; OLIVEIRA, 2005), está dividido em três grupos: o "mercado informacional tradicional" que abrange as bibliotecas públicas, universitárias, escolares, especializadas, centros culturais e arquivos; o "mercado informacional de tendências", que compreende a atuação em centros de informação/documentação em empresas privadas, bancos e bases de dados eletrônicos e digitais, portais de conteúdo e portais na internet ou intranet $e$, o "mercado informacional existente e nãoocupado", que é composto por editoras, empresas privadas, provedores de internet, livrarias, bancos e bases de dados.

Contudo, a literatura comprova que os bibliotecários ainda atuam, principalmente, nos contextos tradicionais do mercado de trabalho. Em um estudo realizado por Cunha et al. (2004), no qual foi traçado um perfil do bibliotecário egresso do Curso de Biblioteconomia da UFSC, constatouse que, no universo pesquisado, a maior parte dos profissionais atuava em bibliotecas universitárias $(24,53 \%)$ e em secretarias e assessorias de informação $(22,65 \%)$.

\subsection{Habilidades e competências do bibliotecário}

Valentim (2000) destaca ainda que o profissional da informação tem o papel de processador e "filtrador" da informação, buscando melhorar a 
qualidade para as demandas por pesquisa apresentadas pelos usuários/clientes. Traçando um perfil desse profissional, a autora ressalta algumas características que considera fundamentais ao bibliotecário, tais como ser criativo, empreendedor, ousado, investigativo e dinâmico.

Fulano elenca as seguintes competências como relevantes para o bibliotecário: habilidade de redação e publicação; habilidade de comunicação, conhecimentos sobre automação informacional; digitalização de recursos; recursos eletrônicos; e gestão de pessoas.

Marcial (1999) e Gonzáles e Tejada (2006, p. 100) relacionam, a partir de uma extensa revisão bibliográfica, as dez competências-chave que devem orientar a formação universitária do bibliotecário: Compreender a estrutura do conhecimento e da informação; Construir a consciência da necessidade de informação; Projetar e implementar estratégias de busca; Localizar os recursos de informação; Avaliar e compreender a informação; Interpretar informações; Comunicar a informação; Aproveitar as expressões artista da informação; Avaliar o processo e o resulta da busca; e, Reconhecer o valor da informação no desenvolvimento da sociedade.

Gonzáles e Tejada (2006) destacam ainda a importância das atitudes, ou habilidades pessoais, para o desenvolvimento profissional. Tais habilidades individuais, também chamadas de transversais, não estão necessariamente relacionadas com a formação técnica, mas são atitudes idiossincráticas. Para Gonzáles e Tejada (2006, p. 101), as habilidades mais relevantes são as seguintes: Saber organizar; Saber antecipar-se; Saber analisar uma situação; Ser rigoroso; Saber elaborar uma síntese; Saber ouvir; Saber ser conciso e preciso; Saber estar disponível; Ser responsável; Saber negociar; Saber ensinar; Saber trabalhar em equipe; Saber autoformar-se; Saber gerir uma equipe; Ter espírito crítico; Ser proativo e autossuficiente; Saber motivar-se; Saber auto avaliar-se.

Em um trabalho desenvolvido por Castro e Diniz de Sá (2002) cujo objetivo consistia em identificar os atributos necessários para a formação dos grupos habilidades/competências e valores/atitudes, bem como quantificar o grau de importância de cada um destes aspectos para um determinado segmento profissional, adotou-se a seguinte categorização:

Habilidades/Competências: aptidões e capacidades propriamente ditas para o desempenho das atividades profissionais;

Valores/Atitudes: predisposição do indivíduo, postura e maneira de agir, sendo significativos na medida em que possibilitam um melhor exercício profissional e uma melhor adaptação às diversas situações de trabalho. (ECHEVESTE, 1998, apud CASTRO; DINIZ DE SÁ, 2002, p. 117) 
Ao citar exemplos para as categorias habilidades/competências e valores/atitudes necessários ao profissional, Castro e Diniz de Sá (2002, p. 119) elencam:

a) habilidades e competências: agente de mudanças; agilidade; antecipação de ameaças/oportunidades; associação de conhecimento prático e teórico; capacidade de decisão; capacidade de formar; comunicação escrita; comunicação oral; concentração; empatia; execução de tarefas dentro do tempo dimensionado; experiência; facilidade de aprendizagem; falar em público; liderança; proposição de soluções; raciocínio lógico; relacionamento humano; trabalho em equipe; e visão sistêmica da empresa.

b) valores e atitudes: abertura para idéias; atitude colaborativa; atitude proativa; ato moral profissional; ato moral social; autoconfiança; bom senso; comprometimento; criatividade; desejo de evolução; educação continuada; flexibilidade; gosto pelo que faz; humildade; integridade; inteligência emocional; intuição; lealdade; e motivação.

\section{Metodologia}

\subsection{A pesquisa}

Esta pesquisa é de natureza descritiva, documental e de campo. O universo da pesquisa foi constituído por 668 bacharéis em Biblioteconomia egressos da ECI/UFMG no período de 2005 a 2010, sendo 33,1\% homens e $66,9 \%$ mulheres. A amostra pesquisada é do tipo não probabilística e foi calculada de maneira que obtivesse margem de erro inferior a $4 \%$ ao nível de $95 \%$ de confiança. Para composição das fórmulas, adotou-se a taxa de desemprego de 2,6\%, encontrada em um estudo do ano de 2000 realizado pelo Sindicato de Bibliotecário do Paraná (BAPTISTA; MUELLER, 2005). A seguir, o detalhamento dos cálculos:

Universo

Proporção de empregados z 95\%

Tamanho da amostra P observado

Tamanho da amostra obtida SE (Margem erro observada) Intervalo de Confiança - LI

\section{8}

0,974

1,96

71,1

0,91

74

0,033

0,877
Proporção de desempregados

Margem de erro (E)

Q observado
0,09

0,026

0,035

0,943

Baseado nos cálculos acima, verificou-se que a amostra deveria ser composta por 70 indivíduos. Considerando-se que 74 bibliotecários 
participaram da pesquisa, o trabalho superou, no quesito amostra, a precisão desejada.

\subsection{Coleta de dados}

O período de coleta de dados compreendeu o ano de 2011. Foi elaborado um questionário semiestruturado dividido em quatro partes, contendo perguntas fechadas e abertas, oportunizando aos respondentes assinalarem as alternativas ou redigir respostas às questões apresentadas. A primeira parte abrangeu questões sobre a formação profissional. A segunda seção referiu-se à inserção no mercado de trabalho e à atuação profissional. A terceira parte aglutina perguntas acerca da perspectiva do público pesquisado, as contribuições do curso para o egresso e do bibliotecário para a ECI/UFMG. E já a quarta parte aborda questões sobre o perfil socioeconômico e demográfico dos bacharéis em Biblioteconomia. Ele foi enviado por email, a uma lista de contatos pessoais que compreendiam 37 indivíduos e foi pedido que estes indicassem outros que se enquadrassem no universo estudado e assim sucessivamente (técnica em cadeias, ou bola-de-neve).

O CRB6 não pôde fornecer e-mails dos bibliotecários cadastrados no conselho, mas encarregou-se de divulgar, em seu site e também enviar por email, o questionário utilizado na pesquisa. Porém, o órgão não dispõe de mecanismos que permita selecionar os destinatários das mensagens (Ex.: Apenas bibliotecários graduados na ECI/UFMG, no período de 2005 a 2010) e, assim, a remessa atingiu, todos os inscritos ativos no CRB6, ou seja, 1727 pessoas.

Devido a agilidade da comunicação eletrônica, determinou-se, a partir da data de encaminhamento e divulgação dos questionários, 15 dias úteis para preenchimento dos mesmos. Dos 37 instrumentos enviados eletronicamente para a lista pessoal de destinatários, resultantes da divulgação no site do Conselho e da remessa, por e-mail, promovida pelo CRB6, 74 questionários foram completamente preenchidos.

\subsection{Tratamento dos dados}

As perguntas fechadas foram aplicadas por meio do Google Docs e preliminarmente tratadas estatisticamente com o auxílio do software SPSS. Para tratamento das questões abertas utilizou-se a análise de conteúdo que, segundo Bardin (1997), é um conjunto de técnicas de análise das comunicações que utilizam procedimentos quantitativos e qualitativos para descrição dos conteúdos das mensagens. De acordo com Collins e Hussey (2005), ela é um método aplicado a coleta de dados no qual o texto é convertido em variáveis numéricas para análise de dados quantitativos.

Para avaliação dos dados quantitativos coletados utilizou-se a análise exploratória de dados e a tabulação cruzada. Segundo Collins e Hussey (2005), a análise exploratória de dados é uma técnica usada para 
sintetizar, descrever ou apresentar dados quantitativos. Também foi aplicada a análise fatorial exploratória que, para Mesquita (2010), é uma técnica multivariada empregada para estimar uma medida e uma relação entre as variáveis observáveis e latentes.

\section{Resultados}

\subsection{Caracterização do grupo estudado}

Dentre os 74 bacharéis que participaram da pesquisa, 96\% tem entre 20 e 40 anos, 68\% estão solteiros, 77\% não possuem filhos e 66\%, residem em Belo Horizonte. Quanto ao período de conclusão do curso, os anos que apresentaram menor número de respondentes foram 2008 e 2009, nove e seis indivíduos respectivamente. Os demais anos obtiveram aproximadamente os mesmos números de respondentes.

Já em relação a inserção no mercado de trabalho e a formação acadêmica, $91 \%$ dos pesquisados possuem pós-graduação (lato ou stricto sensu) e estão trabalhando e somente $9 \%$ (sete indivíduos) possuem apenas graduação e não estão profissionalmente ocupados. Sendo que destes sete, seis concluíram o bacharelado no ano de 2010. Possivelmente, dado o tempo transcorrido entre a conclusão do curso e a realização da pesquisa, os seis bibliotecários ainda não tiveram o tempo suficiente para ingressar no mercado de trabalho. Porém, observando a base de dados, constatou-se que um indivíduo atua em outra área e respondeu negativamente à questão, acredita-se, por entender que apenas os bibliotecários que trabalham na área de formação deveriam responder afirmativamente a pergunta apresentada.

$66,2 \%$ dos pesquisados trabalham em bibliotecas universitárias, escolares, especializadas, arquivos ou centro cultural, $86,5 \%$ recebem remunerações brutas mensais de até $R \$ 4.000,00$ e apenas $13,5 \%$ ganham acima de $\mathrm{R} \$ 4001,00$. A menor renda bruta mensal é oferecida ao profissional que atua em uma biblioteca e as maiores remunerações, acima de $\mathrm{R} \$ 7000,00$ mensais, são oferecidas por uma biblioteca e por uma empresa de economia mista.

Em relação ao sexo e a renda mensal, verifica-se que apenas uma mulher $(1,9 \%)$ recebe até $\mathrm{R} \$ 1.000,00$. Dos profissionais que recebem entre $R \$ 1.000,00$ e $R \$ 2.000,00 ; 44,2 \%$ são mulheres e $31,8 \%$ são homens. Já os que recebem entre $R \$ 2001,00$ e R\$ 4000,00, 54,6\% são homens e $40,40 \%$ são mulheres. No grupo de profissionais cuja renda está entre $R \$ 4.001,00$ e $R \$ 5.000,00,13,6 \%$ são homens e 5,8\% são mulheres e todos os profissionais que recebem acima de $R \$ 5.000,00$ são do sexo feminino.

No que diz respeito às disciplinas que mais favoreceram a qualificação profissional e o ingresso dos pesquisados no mercado de trabalho tem-se: a) Tratamento da informação (37,93\%); b) Administração e suas derivações terminológicas típicas de questões abertas $(11,2 \%)$; c) Catalogação e indexação $(5,17 \%)$ e d) Normalização 
bibliográfica (4,31\%). Quanto às sugestões para melhoria da formação acadêmica em Biblioteconomia na ECI/UFMG, as recomendações mais citadas foram: a) [Mais] Enfoque no mercado de trabalho $(8,7 \%)$; b) Incluir prática e contextualização $(7,6 \%)$; c) Atualização dos professores $(6,5 \%)$ e d) Investir mais em disciplinas de tecnologia de informação $(5,4 \%)$.

Questionados sobre a avaliação pessoal acerca da formação oferecida pelo curso de Biblioteconomia da ECI/UFMG, 70,3\%, classificaram positivamente o curso, dentre estes, apenas 5 não estão inseridos no mercado de trabalho. Verificou-se também que o profissional que recebe os menores rendimentos avaliou a formação como "regular" e os dois que têm melhor renda classificaram-na como "boa".

Constatou-se que a participação, isoladamente, em atividades complementares, como iniciação científica, estágio(s) remunerado(s) e voluntário(s), não garante a inserção no mercado de trabalho. Já em relação à qualificação acadêmica, a maioria dos pesquisados, $82 \%$ não havia iniciado ou concluído outra graduação antes do ingresso no curso de Biblioteconomia e após a conclusão deste curso, apenas $19 \%$ iniciaram outra graduação. Somente $12,2 \%$ dos entrevistados não possuem conhecimentos em inglês, $31,1 \%$ não possuem conhecimentos em Espanhol e 85,1\% em Francês. Aparentemente, conhecimentos de idiomas estrangeiros, isoladamente, não garantem a inserção do bibliotecário no mercado de trabalho.

Dentre os pesquisados, $41,9 \%$ ingressou no emprego atual por meio de seleção por concurso público e $39,2 \%$ por meio de testes e entrevistas. Observou-se também que os concursos públicos foram responsáveis em oferecer a menor (até $\mathrm{R} \$ 1.000,00$ ) e a maior (acima de $\mathrm{R} \$ 7.000,00$ ) remuneração salarial e também a remuneração mais equilibrada, pois 18 profissionais recebem entre $\mathrm{R} \$ 3.001,00$ e $\mathrm{R} \$ 5.000,00$.

Acredita-se que o tempo de permanência no mesmo emprego ou ocupação pode, em virtude de dissídios, reajustes anuais, experiência acumulada e outros fatores, exercer influência elevando, por conseguinte, o valor da remuneração. Nota-se que a porcentagem de indivíduos que recebem entre $R \$ 1.001,00$ e $R \$ 2.000,00$ foi diminuindo na medida em que eles estavam há mais tempo na empresa.

$87,8 \%$ dos entrevistados possuem até três experiências profissionais anteriores a atual. 6,8\% trabalharam ou prestaram serviços a mais de quatro organizações. Talvez, o baixo índice de rotatividade e elevado número de profissionais que permanecem na mesma ocupação/mesmo emprego há mais de três anos, 29 bibliotecários, deve-se ao período abrangido pela pesquisa. Percebe-se que a experiência profissional pode influenciar positivamente na remuneração mensal bruta. Entre os 25 bibliotecários cuja remuneração é superior a $R \$ 3.000,00$, somente seis têm apenas uma experiência. Os dois bibliotecários que ocupam posição no topo da faixa salarial e recebem acima de $R \$ 7.000,00$ têm entre duas e seis experiências profissionais. 
Os dados demonstram que $90 \%$ dos profissionais que concluíram o curso de Biblioteconomia no período pesquisado tiveram o primeiro ingresso no mercado de trabalho com menos de 01 ano após a formatura e, mais de $80 \%$, com menos de 06 meses. As peculiaridades da formação do bibliotecário possibilitam que, além de uma ocupação predominante, ele também atue realizando trabalhos adicionais a fim de complementar a renda, obter experiência, manter-se atualizado ou por quaisquer outros motivos. Assim, constatou-se que 14 entrevistados exerciam atividades profissionais paralelas. Sendo que 13 deles recebem entre mil e quatro mil reais e um recebe acima de sete mil reais.

Procurou-se compreender se a segurança com a formação e qualificação poderia, potencialmente, favorecer o sucesso profissional. 38 pesquisados afirmaram que não se sentem aptos para o mercado de trabalho e 36 acreditam que estão preparados. Constata-se também que a concentração de profissionais despreparados é maior nos níveis de remuneração mais baixos, pois 34 bibliotecários que recebem menos de $\mathrm{R} \$ 4.001,00$ alegam sentir-se insuficientemente preparados para 0 mercado de trabalho. Dentre os quatro profissionais que obtêm renda superior a $\mathrm{R} \$ 5.000,00$, apenas um considerou-se despreparado para competir no universo corporativo.

\subsection{Fatores relevantes na inserção profissional}

Baseado em Minarelli (1995) e Brasil (2003) foram apresentadas aos entrevistados 22 atributos que podem auxiliar na construção e na manutenção da empregabilidade. Pediu-se a eles que os classificassem como irrelevante, pouco relevante, relevante, muito relevante, totalmente relevante, de acordo com a sua percepção pessoal. Os 22 atributos são: Adequação vocacional; 2) Competência profissional; 3) Idoneidade; 4) Saúde física e mental; 5) Reserva financeira e fontes alternativas de renda; 6) Manter-se atualizado; 7) Liderar equipes; 8) Trabalhar em equipe em rede; 9) Capacidade de análise e síntese; 10) Conhecimento de outros idiomas; 11) Capacidade de comunicação; 12) Capacidade de negociação; 13) Agir com ética; 14) Senso de organização; 15) Capacidade empreendedora; 16) Raciocínio lógico; 17) Pró-atividade; 18) Capacidade de concentração 19) Criatividade; 20) Experiências profissionais 21) Contatos profissionais (network); 22) Pós-graduação em curso/concluída.

Posteriormente, realizou-se a análise fatorial exploratória, na qual empregou-se, como método de extração, os componentes principais com normalização de Kaiser, enquanto o critério para definição do número de fatores utilizado foi o do autovalor maior que $1 \mathrm{e}$, como método de rotação, a Varimax.

Inicialmente, optou-se por suprimir os indicadores com cargas fatoriais menores que 0,4 , num total de 7. A análise resultou em três fatores, que juntos explicaram $68,5 \%$ da variação total. Observou-se que o indicador 'Reserva financeira' apresentou comunalidade menor que 0,5, 
demonstrando a necessidade de ser retirado da análise. Após exclusão desse indicador, encontraram-se também três fatores que explicavam $72,22 \%$ da variação total. Constatou-se ainda que 0 indicador 'Competência profissional' apresentou carga fatorial alta em mais de um fator, portanto realizou-se nova análise excluindo este indicador.

A variância total explicada pelos três fatores nesta nova análise foi de $72,91 \%$. Porém, o terceiro fator apresentou carga fatorial alta em apenas um indicador, sugerindo a inutilidade prática deste. Optou-se então por realizar novo ajuste considerando apenas 02 fatores, os quais explicaram 69,57\% da variação observada. Para realização do novo ajuste fez-se necessária a exclusão do indicador 'Adequação profissional', uma vez que este apresentou comunalidade menor que 0,5 . Os resultados são apresentados na Tabela 1.

Tabela 1 - Cargas Fatoriais

\begin{tabular}{l|c|c|c}
\hline \hline \multicolumn{3}{c}{} & \multicolumn{2}{c}{ Carga Fatorial } \\
\hline & Comunalidade & Fator1 & Fator2 \\
\hline Idoneidade & 0,770 & & 0,858 \\
Saúde física e mental & 0,728 & & 0,768 \\
Manter-se atualizado & 0,587 & 0,727 & \\
Liderar equipes & 0,652 & 0,776 & \\
Trabalhar em equipe e em & 0,676 & 0,784 & \\
rede & 0,727 & 0,818 & \\
Capacidade de análise e & & & \\
síntese & 0,657 & 0,795 & \\
Conhecimento de outros & & 0,730 & \\
idiomas & 0,653 & 0,768 & \\
Capacidade de comunicação & 0,670 & & 0,833 \\
Capacidade de negociação & 0,832 & & 0,854 \\
Agir com ética & 0,770 & 0,738 & \\
Senso de organização & 0,626 & \multicolumn{3}{l}{} \\
Capacidade empreendedora & & \\
\hline \hline
\end{tabular}

Fonte: Dados da pesquisa.

A medida de adequação da amostra $\mathrm{KMO}$ foi de 0,873 , acima do limite inferior sugerido. O pressuposto de correlação entre os indicadores também foi satisfeito, uma vez que o p-valor do teste da esfericidade de Bartlett observado foi de 0,000, conforme Tabela 2. 
Tabela 2 - KMO and Bartlett's Test ${ }^{\mathrm{a}}$

\begin{tabular}{|c|c|c|}
\hline \multicolumn{2}{|c|}{$\begin{array}{l}\text { Kaiser-Meyer-Olkin Measure of Sampling } \\
\text { Adequacy. }\end{array}$} & ,873 \\
\hline Bartlett's Test of & Approx. Chi-Square & 641,352 \\
\hline Spher & Df & \\
\hline & Sig. & 0, \\
\hline
\end{tabular}

a. Based on correlations

Fonte: Dados da pesquisa.

Pode-se observar que todos os indicadores apresentam comunalidades acima de 0,5 e carga fatorial alta em apenas um fator. 0 primeiro fator diz respeito às habilidades e competências profissionais e é composto pelos indicadores: Manter-se atualizado; Liderar equipes; Conhecimento de outros idiomas; Trabalhar em equipe e em rede; Capacidade de análise e síntese; Capacidade de comunicação; Capacidade de negociação; Capacidade empreendedora. Já o segundo diz respeito aos valores e atitudes do bibliotecário e abriga os indicadores: Idoneidade; Saúde física e mental; Agir com ética; Senso de organização.

Foi realizada a análise da confiabilidade, unidimensionalidade e validade da solução fatorial. Para análise da confiabilidade calculou-se o coeficiente Alfa de Cronbach. Para o primeiro fator, o valor do Coeficiente foi de 0,922, para o segundo foi de 0,898. Posteriormente, verificaram-se as validades convergente e discriminante, resultados apresentados na Tabela 3. Para isso, criou-se a segunda medida relativa aos fatores utilizando escalas múltiplas. Em seguida, avaliou-se a correlação entre estas medidas e os fatores. A validade convergente é confirmada pelo alto coeficiente de correlação entre os escores fatoriais e as respectivas escalas múltiplas, todos significativos ao nível de $1 \%$.

Tabela 3 - Validade Discriminante e Convergente

\begin{tabular}{c|c|c}
\hline \hline & \multicolumn{2}{|c}{ Escala Múltipla } \\
\hline Fator & 1 & 2 \\
\hline 1 & 0,950 & 0,324 \\
\hline 2 & 0,306 & 0,944 \\
\hline
\end{tabular}

Fonte: Dados da pesquisa.

O resultado atesta a validade discriminante, já que os coeficientes de correlação entre os escores fatoriais e as escalas múltiplas do outro fator são baixos, indicando que cada dimensão mede um conceito próprio.

Por fim, observou-se o perfil dos dois profissionais com maior faixa de renda, considerando-os como sendo aqueles que obtiverem sucesso profissional mais facilmente mensurável. Ambos estão na faixa salarial acima de $R \$ 7.000,00$, são do sexo feminino, solteiras, sem filhos. Uma 
encontra-se na faixa etária de 20 a 30 anos e outra tem entre 30 e 40 anos. Nos dois casos as profissionais têm entre uma e seis experiências anteriores a ocupação atual.

A formação máxima atingida pela primeira bibliotecária é mestrado e da segunda, pós-graduação lato sensu, ambas classificam a formação profissional como boa, não concluíram outra graduação posteriormente à de Biblioteconomia, realizaram cursos de atualização nos últimos 12 meses, trabalham em órgãos públicos, foram selecionadas por concurso público para o cargo que ocupam atualmente, mas não trabalham em Belo Horizonte.

A situação ora relatada, completamente imprevista e, infelizmente, tardiamente detectada, manieta, por ora, a ambição de traçar o perfil do profissional de sucesso no mercado de trabalho da Capital Mineira. Salienta-se que, apesar de ambas as bibliotecárias não atuarem em Belo Horizonte, são egressas da ECI/UFMG no período estudado e, mesmo que não na Capital Mineira, o sucesso salarial das profissionais ratifica a importância inexorável da qualificação para a conquista e manutenção da empregabilidade no mercado de trabalho moderno.

\section{Considerações finais}

A questão inicial apresentada aos participantes da pesquisa, "Você está inserido no mercado de trabalho?", foi afirmativamente respondida por $91 \%$ da amostra de bacharéis egressos da ECI/UFMG. Esse dado, considerado positivo, torna mais otimista o cenário ao somar-se ao fato de que $97 \%$ dos bibliotecários que participaram da pesquisa obtiveram a primeira oportunidade de trabalho em, no máximo, um ano após a formatura e, destes, $51 \%$ já estavam inseridos no mercado antes de completar dois meses de bacharelado.

$96 \%$ dos pesquisados têm entre 20 e 40 anos, estão ainda inseridos, predominantemente, no mercado tradicional de informação e têm contratos sob os regimes celetista ou estatutário. O mercado informacional tradicional ainda é, prevalentemente, responsável pelo acolhimento de bacharéis em Biblioteconomia, e, no caso da Capital Mineira, 68,9\% dos profissionais da informação atuam em bibliotecas, arquivos ou centros culturais. Já o mercado informacional de tendências responde por $16,2 \%$ da ocupação de bibliotecários e o número de profissionais que atuam em editoras, empresas privadas, provedores de internet, bases de dados ou livrarias, 6,8\%, é inferior ao número de egressos que não trabalham na área de formação, ou seja, 8,1\%.

A análise da questão que referiu-se à avaliação das características individuais que auxiliam na construção e manutenção da empregabilidade demonstrou que alguns atributos foram avaliados como irrelevantes ou pouco relevantes pelo grupo pesquisado. Tais atributos compreendem: Adequação vocacional; Reserva financeira e fontes alternativas de renda; Raciocínio lógico; Capacidade de concentração; Pró-atividade; Criatividade; Contatos profissionais (network); Pós-graduação em 
curso/concluída; Experiências profissionais anteriores. A percepção de que network, por exemplo, é pouco relevante para a empregabilidade sugere incoerência com outras avaliações, pois a indicação de amigos, colegas ou familiares, ou em termos atuais e típicos do mercado de trabalho, a rede de relacionamentos, foi responsável pela contratação de significativa parcela dos bibliotecários consultados, situando-se, assim, na terceira posição do ranking de mecanismos responsáveis pela inserção no mercado de trabalho.

Em virtude da formação do bibliotecário, considerava-se possível que, além de uma ocupação preponderante, os profissionais atuassem também realizando trabalhos adicionais e paralelos a fim de complementar a renda, obter experiência, manter-se atualizado ou por quaisquer outros motivos. Contudo, ao serem questionados se exerciam atividade remunerada paralela, apenas $14 \%$ responderam afirmativamente. Tal fato pode ter sido motivado, entre outros, por três aspectos: a) Ausência da necessidade de complementar a renda; b) Falta de oportunidade de assumir outras tarefas profissionais além daquelas já realizadas; c) Ausência de tempo disponível para outra atividade.

Como limitação desta pesquisa, percebe-se a falta de não ter indagado no questionário, os motivos que impedem o bibliotecário de assumir tarefas paralelas à atividade profissional predominante. Tal limitação surge como sugestão para pesquisa futuras.

Outra sugestão para futuras pesquisas advém do aumento vertiginoso de bases virtuais de conhecimento. Diante disso, torna-se imperioso avaliar as habilidades inerentes ao bibliotecário num contexto evidentemente virtual.

\section{Referências}

ARRUDA, M. C. C. et al. Educação, trabalho e delineamento de novos perfis profissionais: o bibliotecário em questão. Ciência da Informação, Brasília, v. 29, n. 3, p. 14-24, 2000.

BAPTISTA, S. G.; MUELLER, S. P. M. Considerações sobre o mercado de trabalho do bibliotecário. Informacion, Cultura y Sociedad, Buenos Aires, n. 12, p. 35-50, 2005.

BARBOSA, R. R. Perspectivas profissionais e educacionais em Biblioteconomia e Ciência da Informação. Ciência da Informação, Brasília, v. 27, n. 1, p. 53-60, 1998.

BARDIN, L. Análise de conteúdo. Lisboa: Edições 70,1997.

BRASIL. Lei no 4.084, de 30 de junho de 1962. Dispõe sobre a profissão de bibliotecário e regula seu exercício. Disponível em: <http://www.planalto.gov.br/ccivil 03/leis/1950-1969/L4084.htm>. Acesso em: 28 set. 2014. 
BRASIL. Ministério do Trabalho e Emprego. Classificação Brasileira de Ocupações. CBO 2002. Brasília: MTE, 2003. 1 CD-ROM.

CASTRO, E. B.; DINIZ DE SÁ, M. A. Habilidades, competências, valores e atitudes: um perfil para os profissionais de computação e informática: In: CONGRESSO DA SOCIEDADE BRASILEIRA DE COMPUTAÇÃO, 22. Florianópolis, 2002. Anais... 2002. v. 4. p. 115-126.

COLLINS, J.; HUSSEY, R. Pesquisa em Administração. Porto Alegre: Bookman, 2005.

CUNHA, M. V. et al. O bibliotecário formado pela Universidade Federal de Santa Catarina: perfil profissional. Perspectivas em Ciência da Informação, Belo Horizonte, v. 9, n. 2, p. 182-195, 2004.

CUNHA, M. B. da; CAVALCANTI, C. R. Dicionário de biblioteconomia e arquivologia. Brasília: Briquet de Lemos/Livros, 2008.

ECHEVESTE, S. et al. Perfil do executivo no mercado globalizado. Revista de Administração Contemporânea, Curitina, v. 3, n. 2, p. 167-186, 1999 apud CASTRO, E. B.; DINIZ DE SÁ, M. A. Habilidades, competências, valores e atitudes: um perfil para os profissionais de computação $e$ informática: In: CONGRESSO DA SOCIEDADE BRASILEIRA DE COMPUTAÇÃO, 22. Florianópolis, 2002. Anais... 2002. v. 4. p. 115-126.

FARIA, M. I. R. de; PERICÃO, M. da G. de. Dicionário do livro: da escrita ao livro eletrônico. São Paulo: Edusp, 2008.

GOMES, D. F. N. et al. Entre a âncora de carreira e a escolha profissional: análise das primeiras definições de carreira dos formandos de curso de Administração em São Paulo. Revista Pensamento \& Realidade, São Paulo, v. 26, n. 1, p. 15-31, jan./abr. 2011.

GONZÁLEZ, J. A. M.; TEJADA, C. Competencias profesionales em el área de la ciência de la información. In: VALENTIM, M. L. P. (Org.). Atuação profissional da área de informação. São Paulo: Polis, 2004. p. 97-110.

HAYNIE, J. M.; SHEPHERD, D. Toward a theory of discontinuous career transition: investigating career transitions necessitated by traumatic life events. Journal of Applied Psychology, Washington, v. 96, n.3, p. 501524, May 2011.

HEIJDEN, B. I. J. M. Van der et al. Age effects on the employability-career success relationship. Journal of Vocational Behavior, v. 74, n. 2, p. 156164, Apr. 2009.

HELAL, D. H. et al. Empregabilidade gerencial no Brasil. RAC Eletrônica, v. 1, n. 2, p. 1-19, 2007. Disponível em: <http://anpad.org.br/periodicos/>. Acesso em: 14 nov. 2008.

KILIMNIK, Z. M. et al. Seriam as âncoras de carreiras estáveis ou mutantes?: um estudo com profissionais de Administração em transição de carreira. Revista Brasileira de Orientação Profissional, São Paulo, v. 9, n. 1, p. 43-60, jun. 2008. 
KUMAR, Bharat. Employability of Library and Information Science Graduates: Competencies Expected versus Taught-A Case Study. DESIDOC Journal of Library \& Information Technology, v. 30, n. 5, p. 74, 2010.

LEMOS, A. H. C. Empregabilidade e individualização da conquista do emprego. In: BALASSIANO, M.; COSTA, I. A. S. Gestão de carreiras: dilemas e perspectivas. São Paulo: Atlas, 2006. p. 49-64.

LEMOS, A. H. C. et al. Empregabilidade e sociedade disciplinar: uma análise do discurso do trabalho contemporâneo à luz de categorias foucaultianas. Organizações \& sociedade, Salvador, v. 18, p. 567-584, 2011.

LOUREIRO, M. F.; JANNUZZI, P. M. Profissional da informação: um conceito em construção. Transinformação, Campinas, v. 17, n. 2, p. 123$151,2005$.

MARCIAL, N. A. Competencias en el uso de la tecnología y los recursos de la información. Transinformação, v. 11, n. 3, p. 194-203, set./dez. 1999.

MESQUITA, J. M. C. de. Estatística multivariada aplicada à administração: guia prático para utilização do SPSS. Curitiba: Ed. CRV, 2010.

MINARELLI, J. A. Empregabilidade: o caminho das pedras. 16. ed. São Paulo: Gente, 1995.

MOTA, F. R. L.; OLIVEIRA, M. Formação e atuação profissional. In: OLIVEIRA, M. (Org.). Ciência da Informação e Biblioteconomia: novos conteúdos e espaços para atuação. Belo Horizonte: UFMG, 2005, p. 97109 apud VALENTIM, M. L. P. Atuação e perspectivas profissionais para o profissional da informação. In: VALENTIM, M. L. P. (Org.). Profissionais da informação: formação, perfil e atuação profissional. São Paulo: Polis, 2000. p. $135-152$.

NADER, Fernanda Milne-Jones; OLIVEIRA, Lúcia Barbosa. Empregabilidade: uma análise histórica e crítica. In: ENCONTRO NACIONAL DE PÓS-GRADUAÇÃO EM ADMINISTRAÇÃO - EnANPAD, 31, 2007, Rio de Janeiro-RJ, Anais... Rio de Janeiro: Anpad, 2007. 1 CD-ROM.

PARTRIDGE, H., MENZIES, V., MUNRO, C. The contemporary librarian: Skills, knowledge and attributes required in a world of emerging technologies. Library \& information science research, v. 32, n. 4, p. 265271, 2010.

SANTA ANNA, J.; PEREIRA, G. Ampliando o campo de atuação bibliotecária: o bibliotecário como consultor informacional. Revista $A C B$ : Biblioteconomia em Santa Catarina, Florianópolis, v. 19, n. 2, p. 163-173, jul./dez. 2014.

SULLIVAN, S. E.; BARUCH, Y. Advances in career theory and research: a critical review and agenda for future exploration. Journal of Management, v. 35, n. 6, p. 1542-1571, Jan. 2009. 
TIEPPO, C. E. et al. Seriam as âncoras de carreira aderente às carreiras inteligentes? Um estudo comparativo entre alunos formandos de um curso de administração de empresas e de hotelaria e turismo. Revista de Gestão Organizacional, v. 4, n. 2, p. 273-293, jul./dez. 2011.

VALENTIM, M. L. P. Atuação e perspectivas profissionais para 0 profissional da informação. In: VALENTIM, M. L. P. (Org.). Profissionais da informação: formação, perfil e atuação profissional. São Paulo: Polis, 2000. p. $135-152$.

VOS, A. De; SOENS, N. Protean attitude and career success: the mediating role of selfmanagement. Journal of Vocational Behavior, v. 73, n. 3, p. 449-456, Dec. 2008.

WILKOSZYNSKI, C. do C.; VIEIRA, F. de O. Carreiras contemporâneas: desafios e contradições frente às mudanças do mundo do trabalho. Desenvolve: Revista de Gestão do Unilasalle, Canoas, v. 2, n. 1, p. 39-58, abr. 2013. 